\title{
Managing vascular risk factors among obese quitters with diabetes: how intensive lifestyle intervention and novel pharmacotherapy can work in concert
}

\author{
DEBASISH KAR ${ }^{1}{ }^{12}$, SAMUEL SEIDU ${ }^{1}$, MELANIE DAVIES ${ }^{1}$, KAMLESH KHUNTI ${ }^{1}$
}

\begin{abstract}
Obese smokers with diabetes are a special risk category for all-cause mortality and major adverse cardiovascular events (MACE). Weight loss and smoking cessation are key interventions advocated for the management of diabetes in almost all the guidelines across the globe. However, there is a substantial risk of weight gain following smoking cessation which may, in some cases, cause a transient worsening of glycaemic control in people with diabetes. The risk of weight gain and the potential for worsening of $\mathrm{HbA}_{1 \mathrm{c}}$ may put off some obese smokers to quit. The cardiometabolic sequelae of smoking cessation in people with and without diabetes are different. The benefit of smoking cessation, in terms of reduced cardiovascular and all-cause mortality, in people without diabetes is evident within three years of quitting. However, it may take up to 10 years for people with diabetes to get this benefit. Post-cessation weight gain is much more detrimental to obese quitters with diabetes than those without. The aim of this review is to explore how best these highrisk individuals can be supported to remain abstinent long-term, and manage their vascular risk profile proactively, by concerted lifestyle intervention with judicious use of new and novel pharmacotherapy.

Br J Diabetes 2017;17:19-23
\end{abstract}

Key words: diabetes, obesity, vascular risk factors, quitting

\section{Background}

Obese smokers constitute a special risk group for the vascular complications of diabetes. A constellation of aetiologically linked pathophysiological processes contributes to the higher prevalence of microvascular and macrovascular complications in obese smokers

Diabetes Research Centre, University of Leicester, UK

Derbyshire Community Health Services NHS Foundation Trust, UK

Address for correspondence: Dr Debasish Kar

Leicester Diabetes Research Centre, Gwendolen Road, Leicester

LE5 4PW, UK

E-mail: d.kar@nhs.net; dk209@leicester.ac.uk

http://dx.doi.org/10.15277/bjd.2017.120 with diabetes. ${ }^{1,2}$ Insulin resistance appears to be the linking thread between obesity, smoking and type 2 diabetes (T2DM), which are often accompanied by hypertension, dyslipidaemia and endothelial dysfunction. ${ }^{3}$ Smoking is considered to be closely associated with insulin resistance, which appears to potentiate the vascular risk profiles in obese people with T2DM. ${ }^{4}$ Several studies have shown that both smoking and obesity accelerate insulin resistance and $\beta$-cell apoptosis. ${ }^{5-7}$ Interestingly, as the global prevalence of obesity is rising, so is the prevalence of diabetes, hypertension and dyslipidaemia, suggesting that obesity, T2DM, hypertension and dyslipidaemia might have a common and shared pathophysiology.8,9 Both obesity and smoking impact on several key portals of glucose, lipid and blood pressure regulating mechanisms, leading to hyperglycaemia, dyslipidaemia and hypertension, which are key precursors for both macrovascular and microvascular complications in diabetes. A recent systematic review and meta-analysis by Pan et al revealed that smokers with T2DM have a significantly higher rate of all-cause mortality and vascular complications than non-smokers with T2DM. ${ }^{10}$ Similar associations have been found in obese people with T2DM, who have a higher prevalence of microvascular and macrovascular complications than non-obese individuals with diabetes. 9,11

The objective of this review is to evaluate the impact of smoking cessation on the vascular risk profiles of obese people with diabetes, and to explore how the new and novel pharmacotherapy can play a complementary role in association with aggressive lifestyle intervention. Important lifestyle interventions like smoking cessation should continue to be at the centre of the management of diabetes, as the risk of diabetic complications is significantly higher in smokers than in non-smokers. ${ }^{12,13}$

\section{Relationship of obesity, smoking and vascular risk profiles}

Obesity follows a trajectory of interlinked metabolic disarray from insulin resistance, fasting hyperglycaemia and impaired glucose tolerance, leading to T2DM. ${ }^{14}$ Smoking seems to play a contributory role in all the phases of this trajectory. In addition to expediting insulin resistance - and its subsequent sequelae on glucose - and lipid metabolism, obesity and smoking are considered to be independent risk factors in macroangiopathy and microangiopathy. ${ }^{15,16}$ Obesity is linked with hypertension in 
people with or without diabetes. ${ }^{17}$ Smoking is also associated with an acute rise in blood pressure and an accelerated rate of vasculopathy in people with diabetes..$^{18-20}$ Both obesity and smoking are linked with atherogenic dyslipidaemia, which are considered to be the forerunners of vascular complications in diabetes. ${ }^{21,22}$ Both the Diabetes Control and Complications Trial (DCCT) and the United Kingdom Prospective Diabetes Study (UKPDS) demonstrated that an effective management of hypertension, dyslipidaemia, obesity and smoking cessation are as important as - if not more than - glycaemic control in the management of diabetes. ${ }^{23,24}$ Most recently, 21-year follow-up data on the original cohort of the STENO-2 study demonstrated an average increase of 7.9 years of life expectancy in the group who received a target-driven multifactorial intervention compared with conventional treatment. ${ }^{25}$ Smoking cessation was one of the key components of this multifactorial intervention.

However, a recent systematic review and meta-analysis of a large cohort $(n=101,000)$ of smokers, non-smokers and quitters with diabetes demonstrated that there was a graded relationship between quitting smoking and decline in $\mathrm{HbA}_{1}$; ; the longer the duration of abstinence, the lower the $\mathrm{HbA}_{1 c} .{ }^{26} \mathrm{~A}$ retrospective study on The Health Improvement Network (THIN) database by Lycett et al showed that the $\mathrm{HbA}_{1 \mathrm{c}}$ could rise for up to about three years after smoking cessation compared with continued smokers in people with T2DM. ${ }^{27}$ A recent World Health Organization (WHO) study showed that the risk of all-cause mortality was higher for recent quitters (1-9 years) than for those who quit earlier (>10 years) compared with non-smokers. The relative risk of all-cause mortality in these two groups was 1.53 (95\% $\mathrm{Cl} 1.19$ to $1.97 ; \mathrm{p}=0.001)$ and $1.25(95 \% \mathrm{Cl} 1.03$ to 1.52 ; $\mathrm{p}=0.02$ ), respectively. ${ }^{28,29}$

\section{Impact of quitting and weight loss in obese smokers with T2DM}

Several studies have shown improved cardiometabolic profiles following smoking cessation and weight loss in people with diabetes. The ADVANCE (Action in Diabetes and Vascular Disease: Preterax and Diamicron modified release Controlled Evaluation) trial with 11,140 participants with T2DM demonstrated a 30\% reduction in all-cause mortality after smoking cessation. ${ }^{2}$ The Nurses' Health Study also showed a significant improvement in all-cause and cardiovascular mortality after smoking cessation in those with T2DM. ${ }^{30}$ Studies have shown that the benefit of quitting is precipitously reflected upon people without diabetes, as evidenced by reduced cardiovascular mortality, to the level of non-smokers within three years after quitting. ${ }^{31}$ However, the benefit of quitting and mortality is not so prompt in quitters with diabetes. The Multinational Study of Vascular Disease (MSVDD), a large epidemiological study, demonstrated that it might take up to 10 years for the cardiovascular mortality in quitters with diabetes to reach the level of non-smokers. ${ }^{28}$

Similar benefits can be gained by weight loss in obese people with T2DM. Weight loss in obese smokers improves a number of cardiometabolic parameters. Insulin sensitivity seems to improve significantly even with moderate weight loss, which is reflected on the $\mathrm{HbA}_{1 \mathrm{c}}$ and lipid profile. The Look AHEAD trial examined the influence of weight loss on obese people with T2DM. ${ }^{32}$ After four years of follow-up, obese and overweight people with T2DM managed to lose $6.15 \%$ of body weight from baseline by intensive lifestyle intervention while the control group, with standard diabetes support and education, managed to lose $0.88 \%$. These two groups showed a difference in a number of cardiometabolic parameters including $\mathrm{HbA}_{1 \mathrm{c}}(-0.36 \%$ vs. $0.09 \%, p<0.001)$, systolic blood pressure ( -5.33 vs. -2.97 $\mathrm{mmHg}, \mathrm{p}<0.001)$, diastolic blood pressure $(-2.92$ vs. -2.42 $\mathrm{mmHg}, \quad \mathrm{p}<0.012$ ), HDL cholesterol (3.67 vs. $1.97 \mathrm{mg} / \mathrm{dL}$, $p<0.0001)$ and triglyceride level $(-25.56$ vs. $-19.75 \mathrm{mg} / \mathrm{dL}$, $p<0.0006)$. The longer the weight loss was sustained, the better was the cardiovascular outcome. ${ }^{32,33}$

\section{Barriers to smoking cessation in obese smokers}

Despite an all-out drive worldwide to discourage smoking in people with T2DM, the prevalence of smoking in people with and without diabetes remains comparable. ${ }^{34}$ The risk of further weight gain and worsening glycaemic control are the commonest arguments against quitting. In a recent systematic review and meta-analysis, Tian et al demonstrated that, by the 12th month after quitting, the average weight gain was $4.10 \mathrm{~kg} .{ }^{35}$ There was some anecdotal evidence that this weight gain might perpetuate a rise in $\mathrm{HbA}_{1 \mathrm{c}} .27,36 \mathrm{How}$ ever, there is undisputable evidence to suggest that post-cessation weight gain and its adverse effects on $\mathrm{HbA}_{1 c}$ can be offset by incorporating quitting as part of a structured lifestyle intervention. ${ }^{37,38}$

\section{Intensive lifestyle intervention following smoking cessation}

Structured lifestyle interventions have consistently shown promising prospects of mitigating the weight gain in quitters with T2DM. A community-based cohort study on the Framingham Offspring Study demonstrated that recent quitters with diabetes gained more weight than quitters without diabetes; median weight gain was 3.6 $\mathrm{kg}(\mathrm{IQR}-1.4$ to 8.2$)$ and $2.7 \mathrm{~kg}$ (IQR -0.5 to 6.4$)$, respectively. ${ }^{39}$ Stamford et al demonstrated that, following smoking cessation, the average daily caloric intake was increased by $277 \mathrm{kcal}$ without any increase in physical activities. ${ }^{40}$ The study postulated that $69 \%$ of this post-cessation weight gain was attributed to increased calorie consumption, and the remaining $21 \%$ was due to the downregulation of basal metabolic rate. Interestingly, if an exercise programme equivalent to about 45 minutes of extra walking a day accompanied the smoking cessation programme, this weight gain could be reduced to $1.3 \mathrm{~kg}$ over a two-year period. ${ }^{41}$ Integrating behavioural therapy to include dietary intervention, and promoting physical activities alongside pharmacotherapy, not only offset the weight gain but also increased the quit rate from $2-5 \%$ to $15-20 \% .{ }^{42,43}$ Diabetes Education and Self-Management for Ongoing and Newly Diagnosed (DESMOND) is a very successful integrated lifestyle intervention model. 44,45 In recent obese quitters with diabetes, a DESMOND plus model (new and novel pharmacotherapy plus DESMOND) could be a step forward in the traditional smoking cessation programme. 


\section{New and novel pharmacotherapy}

In the last 10 years, significant progress has been made in the field of pharmacotherapy to reduce the vascular risk factors in people with diabetes. Metformin is an effective initial oral medication for obese smokers with T2DM because of its combined hypoglycaemic and cardioprotective properties. Multiple studies have demonstrated that metformin has a beneficial role on vascular risk profiles over and above its glucose-lowering effects. $.6,47$ The American Diabetes Association and the European Association for Study of Diabetes published a joint statement recommending metformin as the firstline treatment for obese people with diabetes. 48,49 In a recent study, the researchers have demonstrated that smokers who were on metformin had an $8 \%$ increased risk of major adverse cardiovascular events (MACE) compared with 32\% for those who were not on metformin. ${ }^{50}$ Similarly, in the Biguanides and Prevention of the Risks of Obesity (BIGPRO) trial, participants who were on metformin achieved significantly more weight loss than those who were on placebo $\left(-2.0 \mathrm{~kg}\right.$ and $-0.8 \mathrm{~kg}$, respectively)..$^{51}$ Therefore, we can conclude that, in obese current and ex-smokers with T2DM, concurrent treatment with metformin attenuates the observed higher risk of MACE and all-cause mortality.

However, if metformin is not tolerated or contraindicated, sulfonylureas should be considered with caution as an alternative agent. Sulfonlyureas are obesogenic drugs and can cause hypoglycaemia, which can be a deterrent to quitting and to remaining abstinent. ${ }^{52} \mathrm{~A}$ better option for pharmacotherapy could be other novel glucose-lowering agents which are weight neutral or have weight-reducing properties, such as sodium glucose co-transport2 (SGLT-2) inhibitors and incretin-based agents such as dipeptidyl peptidase-4 (DPP-4) inhibitors and glucagon-like peptide-1 receptor agonist (GLP1-RA).

SGLT-2 inhibitors are a group of orally administered glucoselowering drugs which are not insulin dependent and therefore do not cause hypoglycaemia and weight gain. ${ }^{53} \mathrm{~A}$ recent metaanalysis comparing SGLT-2 inhibitors with placebo showed that the mean reduction in $\mathrm{HbA}_{1 \mathrm{c}}$ with $\mathrm{SGLT}-2$ inhibitors was $-0.66 \%$ compared with placebo and the mean weight loss with SGLT-2 inhibitors was $-1.8 \mathrm{~kg}$ compared with placebo. A similar outcome was noted for blood pressure in another meta-analysis comparing SGLT-2 inhibitors. Compared with placebo, the mean reduction in systolic and diastolic blood pressure with SGLT-2 inhibitors was $-4 \mathrm{mmHg}$ and $-1.6 \mathrm{mmHg}$ from baseline, respectively. ${ }^{54}$ For obese quitters, this group of drugs can be considered in preference to insulin secretagogues.

Incretin-based drugs GLP1-RA and DPP-4 inhibitors are a group of glucose-lowering drugs which have additional weightreducing or weight-neutral effects. They can be used as suitable agents to deal with the weight gain following smoking cessation in obese smokers with T2DM. GLP-1RA delivers a supra-physiological level of GLP-1, resistant to biodegradation by endogenous DPP-4. In addition to glycaemic control, GLP-1RAs are useful agents for weight loss, control of blood pressure and managing dyslipidaemia. ${ }^{55}$ DPP-4 inhibitors, on the other hand, are weightneutral glucose-lowering drugs with a favourable outcome on a number of cardiovascular risk factors including $\mathrm{HbA}_{1 \mathrm{c}}$ and lipid

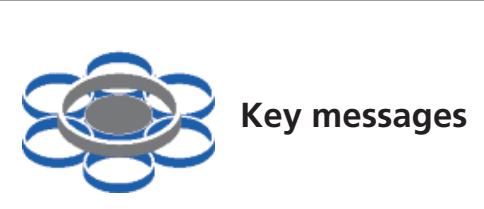

- The cardiometabolic sequelae of quitting are different in people with and without diabetes

- Further weight gain and a transient deterioration of glycaemic control in obese smokers can be challenging after quitting

- Quitting smoking for $<10$ years does not provide any meaningful cardiovascular protection for obese smokers with diabetes

- Smoking cessation should be offered as part of a structured multifactorial intervention package such as DESMOND

- Judicious use of new and novel therapy for a selected group of quitters can help to keep them abstinent while improving their overall vascular risk profiles

profile. ${ }^{56}$ A recent meta-analysis compared GLP-1RAs and DPP-4 inhibitors for their glucose-lowering efficacy and weight-reducing properties. Long-acting GLP-1RAs showed a greater reduction in $\mathrm{HbA}_{1 \mathrm{c}}$ from baseline than DPP-4 inhibitors. Both short- and longacting GLP-1RAs were associated with significant weight loss from baseline, while DPP-4 inhibitors were associated with a trend towards weight loss. ${ }^{57}$

\section{Conclusion}

Obese smokers with diabetes are a special risk category before and after smoking cessation. They should be actively supported to quit and remain abstinent long-term. Smoking cessation should be offered as part of a structured multifactorial intervention strategy. A targeted multifactorial intervention alongside a judicious use of non-insulin-based glucose-lowering agents with added weightneutral or weight-reducing properties will help to avert the weight gain and its deleterious impact on glycaemic control. In order to address the dyslipidaemia and associated risk of adverse cardiovascular events, this group should be treated aggressively with HMG Co-A reductase (statin therapy) inhibitors.

\section{Conflict of interest None.}

Funding DK is employed by the Derbyshire Community Health Services NHS Foundation Trust. However, it does not have any influence on the contents of the article. This review was supported by a fellowship grant from the National Institute for Health Research Collaboration for Leadership in Applied Health Research and Care - East Midlands (NIHR CLAHRC-EM) and NIHR Leicester- Loughborough Diet, Lifestyle and Physical Activity Biomedical Research Unit, which is a partnership between the University Hospitals of Leicester NHS Trust, Loughborough University and the University of Leicester.

\section{References}

1. Chaturvedi N, Stephenson JM, Fuller JH. The relationship between smoking and microvascular complications in the EURODIAB IDDM Complications Study. Diabetes Care 1995;18(6):785-92. 
https://doi.org/10.2337/diacare.18.6.785

2. Blomster Jl, Woodward M, Zoungas S, et al. The harms of smoking and benefits of smoking cessation in women compared with men with type 2 diabetes: an observational analysis of the ADVANCE (Action in Diabetes and Vascular Disease: Preterax and Diamicron modified release Controlled Evaluation) trial. BMJ Open 2016;6(1):e009668-2015009668. http://dx.doi.org/10.1136/bmjopen-2015-009668

3. Samuel VT, Shulman GI. Integrating mechanisms for insulin resistance: common threads and missing links. Cell 2012;148(5):852-71. http://dx.doi.org/10.1016/j.cell.2012.02.017

4. Magis D, Geronooz I, Scheen AJ. [Smoking, insulin resistance and type 2 diabetes]. Rev Med Liege 2002;57(9):575-81.

5. Poitout $V$, Robertson RP. Glucolipotoxicity: fuel excess and $\beta$-cell dysfunction. Endocr Rev 2008;29(3):351-66. https://doi.org/10.1210/er.2007-0023

6. Bergman BC, Perreault L, Hunerdosse D, et al. Novel and reversible mechanisms of smoking-induced insulin resistance in humans. Diabetes 2012;61(12):3156-66. http://dx.doi.org/10.2337/db12-0418.

7. Jurgens $C A$, Toukatly $M N$, Fligner $C L$, et al. $\beta$-cell loss and $\beta$-cell apoptosis in human type 2 diabetes are related to islet amyloid deposition. Am J Pathol 2011;178(6):2632-40. http://dx.doi.org/10.1016/j.ajpath.2011.02.036

8. DeFronzo RA, Ferrannini E. Insulin resistance. A multifaceted syndrome responsible for NIDDM, obesity, hypertension, dyslipidemia, and atherosclerotic cardiovascular disease. Diabetes Care 1991;14(3):173-94. https://doi.org/10.2337/diacare.14.3.173

9. De Boer IH, Sibley SD, Kestenbaum B, et al. Central obesity, incident microalbuminuria, and change in creatinine clearance in the Epidemiology of Diabetes Interventions and Complications study. JASN 2007;18:23543. $h$ ttp://dx. doi.org/10.1681/ASN.2006040394

10. Pan A, Wang Y, Talaei M, Hu FB. Relation of smoking with total mortality and cardiovascular events among patients with diabetes mellitus: a meta-analysis and systematic review. Circulation 2015;132(19):1795804. http://dx. doi.org/10.1161/CIRCULATIONAHA.115.017926

11. DeFronzo RA, Ferrannini E. Insulin resistance. A multifaceted syndrome responsible for NIDDM, obesity, hypertension, dyslipidemia, and atherosclerotic cardiovascular disease. Diabetes Care 1991;14(3):173-94. https://doi.org/10.2337/diacare.14.3.173

12. Delaimy WKA. Smoking and risk of coronary heart disease among women with type 2 diabetes mellitus. JAMA 2002;287(19):2478.

13. Lanza GA, Spera FR, Villano A, et al. Effect of smoking on endotheliumindependent vasodilatation. Atherosclerosis 2015;240(2):330-2. http://dx.doi.org/10.1016/j.atherosclerosis.2015.03.041

14. Rodríguez A. Risk factors associated with metabolic syndrome in type 2 diabetes mellitus patients according to World Health Organization, Third Report National Cholesterol Education Program, and International Diabetes Federation definitions. Diabetes Metab Syndr Obes: Targets and Therapy 2011:1-4. http://dx.doi.org/10.2147/DMSOTT.S13457

15. Afghahi H, Cederholm J, Eliasson B, et al. Risk factors for the development of albuminuria and renal impairment in type 2 diabetes - the Swedish National Diabetes Register (NDR). Nephrol Dial Transplant 2011;26:1236-43. http://dx.doi.org/10.1093/ndt/gfq535

16. Agewall S, Fagerberg B. Risk factors that predict development of microalbuminuria in treated hypertensive men. The Risk Factor Intervention Study Group. Angiology 1996;47:963-72. https://doi.org/10.1177/000331979604701005

17. Papanas N, Katsiki N, Putz Z, Mikhailidis DP. Diabetes, obesity and vascular disease - an update. Curr Pharm Des 2013;19:4900-03.

18. Kiowski W, Linder L, Stoschitzky K, et al. Diminished vascular response to inhibition of endothelium-derived nitric oxide and enhanced vasoconstriction to exogenously administered endothelin-1 in clinically healthy smokers. Circulation 1994;90(1):27-34. https://doi.org/10.1161/01.CIR.90.1.27

19. Sayk F, Iwen KA, Lehnert H. Diabetes and hypertension. Deutsche medizinische Wochenschrift 2009;134:2296-301.

20. Martinez Ocana JC, Romero R. Tobaccoism and albuminuria in hypertension and diabetes: is tobacco also harmful for the kidney? Med Clin (Barc) 1999;112:176-8.

21. Kong C, Nimmo L, Elatrozy T, et al. Smoking is associated with increased hepatic lipase activity, insulin resistance, dyslipidaemia and early athero- sclerosis in type 2 diabetes. Atherosclerosis 2001;156(2):37-8 https://doi.org/10.1016/S0021-9150(00)00664-X

22. Parving HH, Gall MA, Nielsen FS. Dyslipidaemia and cardiovascular disease in non-insulin-dependent diabetic patient with and without diabetic nephropathy. J Intern Med 1994; Suppl 736:89-94.

23. Anon. Effect of intensive diabetes management on macrovascular events and risk factors in the Diabetes Control and Complications Trial. Am J Cardiol 1995;75(14):894-903. https://doi.org/10.1016/S0002-9149(99)80683-3

24. Turner RC, Millns H, Neil HA, et al. Risk factors for coronary artery disease in non-insulin dependent diabetes mellitus: United Kingdom Prospective Diabetes Study (UKPDS: 23). BMJ 1998:316(7134):823-8.

https://doi.org/10.1136/bmj.316.7134.823

25. Gæde P, Oellgaard J, Carstensen B, et al. Years of life gained by multifactorial intervention in patients with type 2 diabetes mellitus and microalbuminuria: 21 years follow-up on the Steno-2 randomised trial. Diabetologia 2016;59(11):2298-307. http://dx.doi.org/10.1007/s00125-016-4065-6

26. Kar D, Gillies C, Zaccardi F, et al. Relationship of cardiometabolic parameters in non-smokers, current smokers, and quitters in diabetes: a systematic review and meta-analysis. Cardiovasc Diabetol 2016;15(1):158. http://dx.doi.org/10.1186/s12933-016-0475-5

27. Lycett $D$, Nichols $L$, Ryan $R$, et al. The association between smoking cessation and glycaemic control in patients with type 2 diabetes: a THIN database cohort study. Lancet Diabetes Endocrinol 2015;3(6):423-30. http://dx.doi.org/10.1016/S2213-8587(15)00082-0

28. Chaturvedi N, Stevens L, Fuller JH. Which features of smoking determine mortality risk in former cigarette smokers with diabetes? The World Health Organization Multinational Study Group. Diabetes Care 1997;20(8):1266-72. https://doi.org/10.2337/diacare.20.8.1266

29. Chaturvedi N, Fuller JH. Mortality risk by body weight and weight change in people with NIDDM. The WHO Multinational Study of Vascular Disease in Diabetes. Diabetes Care 1995;18(6):766-74. https://doi.org/10.2337/diacare.18.6.766

30. Al-Delaimy WK, Willett WC, Manson JE, Speizer FE, Hu FB. Smoking and mortality among women with type 2 diabetes: The Nurses' Health Study cohort. Diabetes Care 2001;24(12):2043-8.

https://doi.org/10.2337/diacare.24.12.2043

31. Dobson AJ, Alexander HM, Heller RF, Lloyd DM. How soon after quitting smoking does risk of heart attack decline? J Clin Epidemiol 1991:44(11):1247-53. https://doi.org/10.1016/0895-4356(91)90157-5

32. Look AHEAD Research Group, Pi-Sunyer X, Blackburn G, Brancati FL, et al. Reduction in weight and cardiovascular disease risk factors in individuals with type 2 diabetes: one-year results of the look AHEAD trial. Diabetes Care 2007;30(6):1374-83. https://doi.org/10.2337/dc07-0048

33. Wing RR, Lang W, Wadden TA, et al. Benefits of modest weight loss in improving cardiovascular risk factors in overweight and obese individuals with type 2 diabetes. Diabetes Care 2011;34(7):1481-6. http://dx.doi.org/10.2337/dc10-2415

34. Malarcher AM, Ford ES, Nelson DE, et al. Trends in cigarette smoking and physicians' advice to quit smoking among people with diabetes in the U.S. Diabetes Care 1995;18(5):694. https://doi.org/10.2337/diacare.18.5.694

35. Tian J, Venn A, Otahal P, Gall S. The association between quitting smoking and weight gain: a systemic review and meta-analysis of prospective cohort studies. Obes Rev 2015;16(10):883-901. http:dx.doi.org/10.1111/obr.12304

36. Aubin HJ, Farley A, Lycett D, Lahmek P, Aveyard P. Weight gain in smokers after quitting cigarettes: meta-analysis. BMJ 2012;345:e4439. http://dx.doi.org/10.1136/bmj.e4439

37. Aveyard $P$, Lycett $D$, Farley A. Managing smoking cessation related weight gain. Pol Arch Med Wewn 2012;122(10):494-8.

38. Levine MD, Marcus MD, Perkins KA. Women, weight, and smoking: a cognitive behavioral approach to women's concerns about weight gain following smoking cessation. Cognit Behav Pract 2003;10(2):105-11. https://doi.org/10.1016/\$1077-7229(03)80018-4

39. Clair C, Rigotti NA, Porneala B, et al. Association of smoking cessation and weight change with cardiovascular disease among adults with and without diabetes. JAMA 2013;309(10):1014-21. http://dx.doi.org/10.1001/jama.2013.1644

40. Stamford BA, Matter S, Fell RD, Papanek P. Effects of smoking cessation 
on weight gain, metabolic rate, caloric consumption, and blood lipids. Am J Clin Nutr 1986;43(4):486-94.

41. Kawachi I, Troisi RJ, Rotnitzky AG, Coakley EH, Colditz GA. Can physical activity minimize weight gain in women after smoking cessation? Am J Public Health 1996;86(7):999-1004. https://doi.org/10.2105/AJPH.86.7.999

42. Hughes JR, Keely J, Naud S. Shape of the relapse curve and long-term abstinence among untreated smokers. Addiction 2004;99(1):29-38. https://doi.org/10.1111/j.1360-0443.2004.00540.x

43. Le Foll B, Melihan-Cheinin P, Rostoker G, Lagrue G. Smoking cessation guidelines: evidence-based recommendations of the French Health Products Safety Agency. Eur Psychiatry 2005;20(5):431-41. https://doi.org/10.1016/j.eurpsy.2004.12.008

44. Dinneen, Davies MJ, Heller S, et al. Effectiveness of the Diabetes Education and Self Management for Ongoing and Newly Diagnosed (DESMOND) Programme for people with newly diagnosed type 2 diabetes: cluster randomised controlled trial. BMJ 2008;336(7642):491-5. http://dx.doi.org/10.1136/bmj.39474.922025.BE

45. Skinner TC, Carey ME, Cradock S, et al. Depressive symptoms in the first year from diagnosis of type 2 diabetes: results from the DESMOND trial. Diabet Med 2010;27(8):965-7 http://dx.doi.org/10.1111/j.1464-5491.2010.03028.x

46. Viberti G, Lachin J, Holman R, et al. A Diabetes Outcome Progression Trial (ADOPT): baseline characteristics of type 2 diabetic patients in North America and Europe. Diabetic Medicine 2006;23:1289-94.

47. Inzucchi SE, Bergenstal RM, Buse JB, et al. Management of hyperglycemia in type 2 diabetes, 2015: a patient-centered approach: update to a position statement of the American Diabetes Association and the European Association for the Study of Diabetes. Diabetes Care 2015; 38(1):140-09. http://dx.doi.org/10.2337/dc14-2441

48. Heaf J. Metformin in chronic kidney disease: time for a rethink. Peritoneal Dialysis Int 2014;34(4):353-7.

http://dx.doi.org/10.3747/pdi.2013.00344

49. Turner RC, Cull CA, Frighi V, Holman RR. Glycemic control with diet, sulfonylurea, metformin, or insulin in patients with type 2 diabetes mellitus: progressive requirement for multiple therapies (UKPDS 49). UK Prospective Diabetes Study (UKPDS) Group. JAMA 1999;281(21):200512. https://doi.org/10.1001/jama.281.21.2005

50. Paul SK, Klein K, Majeed A, Khunti K. Association of smoking and concomitant metformin use with cardiovascular events and mortality in people newly diagnosed with type 2 diabetes. J Diabetes 2016;8(3):354-62. http://dx.doi.org/10.1111/1753-0407.12302

51. Fontbonne A, Charles MA, Juhan-Vague I, et al. The effect of metformin on the metabolic abnormalities associated with upper-body fat distribution. BIGPRO Study Group. Diabetes Care 1996;19(9):920-6. https://doi.org/10.2337/diacare.19.9.920

52. Phung OJ, Scholle JM, Talwar M, Coleman Cl. Effect of noninsulin antidiabetic drugs added to metformin therapy on glycemic control, weight gain, and hypoglycemia in type 2 diabetes. JAMA 2010;303(14):14108. http://dx.doi.org/10.1001/jama.2010.405

53. Chao ECDO. SGLT-2 inhibitors: a new mechanism for glycemic control. Clin Diabetes 2014;32(1):4-11. http://dx.doi.org/10.2337/diaclin.32.1.4

54. Baker WL, Smyth LR, Riche DM, Bourret EM, Chamberlin KW, White WB. Effects of sodium-glucose co-transporter 2 inhibitors on blood pressure: a systematic review and meta-analysis. I Am Soc Hypertens 2014;8(4):262-75.e9. http:dx.doi.org/10.1016/j.jash.2014.01.007

55. Davidson JA. Advances in therapy for type 2 diabetes: GLP-1 receptor agonists and DPP-4 inhibitors. Cleve Clin J Med 2009;76(Suppl 5):S2838. https://doi.org/10.3949/ccjm.76.s5.05

56. Kawalec P, Mikrut A, Łopuch S. The safety of dipeptidyl peptidase-4 (DPP-4) inhibitors or sodium-glucose cotransporter 2 (SGLT-2) inhibitors added to metformin background therapy in patients with type 2 diabetes mellitus: a systematic review and meta-analysis. Diabetes Metab Res Rev 2014;30(4):269-83. https://doi.org/10.1002/dmrr.2494

57. Aroda VR, Henry RR, Han J, et al. Efficacy of GLP-1 receptor agonists and DPP-4 inhibitors: meta-analysis and systematic review. Clin Ther 2012; 34(6):1247-58.e22. http://dx.doi.org/10.1016/j.clinthera.2012.04.013

Dexcom $\mid$ mobie

See and Treat Diabetes with

More Options Than Ever Before with the

Dexcom G5 ${ }^{\circledR}$ Mobile Continuous
Glucose Monitoring (CGM) System

Continuous Glucose Monitoring (CGM) reveals what no meter can. Unlike fingersticks that give a number for a single point in time, the Dexcom G5 Mobile CGM System displays glucose readings in real time, so you always know the speed and direction of glucose levels.

With the Dexcom G5 Mobile CGM System, making treatment decisions has never been easier as no confirmatory fingersticks are needed ${ }^{*}$. Plus, with consistent, accurate ${ }^{1}$ sensing performance and real-time remote monitoring with customisable alerts and alarms, the Dexcom G5 Mobile CGM System provides more options to see and treat diabetes.

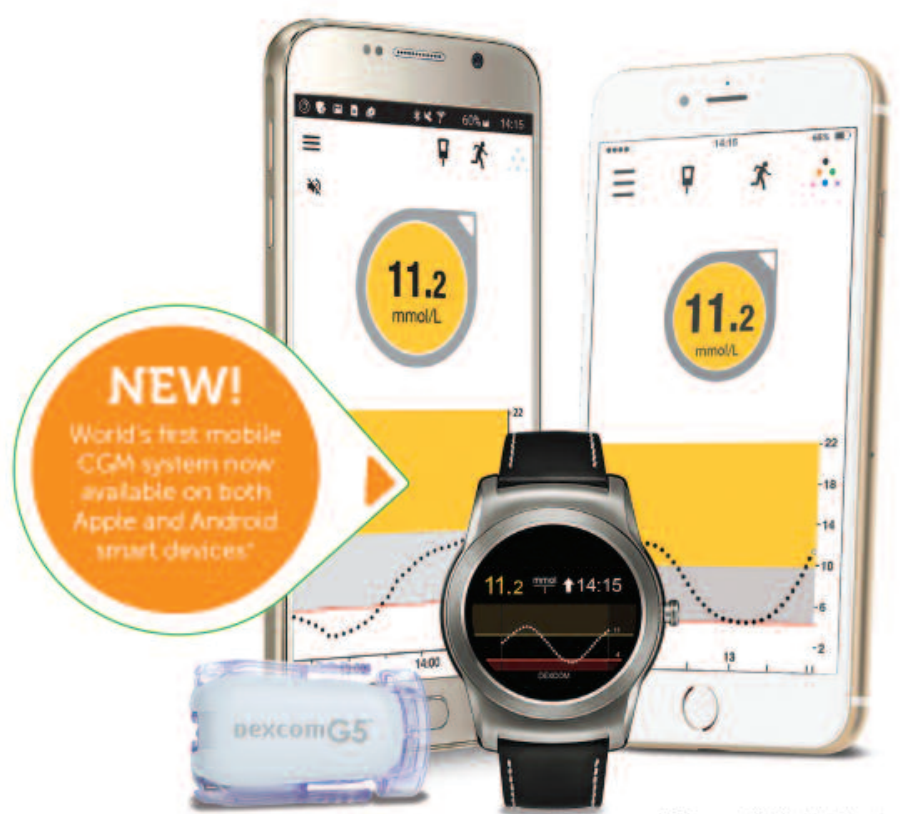

A Dexcon G5 Mobile Receiver can be acquired as an optional display device. - To view a list of compatible devices, visit www dexcom.com/compatibility. "If your glucose alerts and readings do not match your symptoms or expectations or you are taking medications containing paracetamol/acetaminophen.

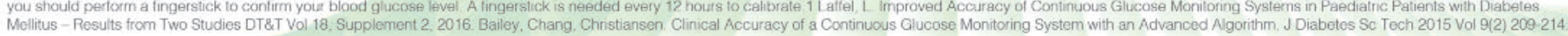

